\title{
Aportes del pensamiento latinoamericano al trabajo social crítico
}

\author{
Contributions of latin american thought \\ critical social work \\ LUIS ViVERO ARriagadAa \\ aTrabajador Social, Doctor en Procesos Sociales y Políticos en América latina. \\ Académico Departamento de Trabajo Social, Universidad Católica de Temuco- Chile \\ $\measuredangle$ luisvive@gmail.com
}

\begin{abstract}
RESUMEN
El objetivo central de este trabajo fue analizar críticamente los aportes del Pensamiento Latinoamericano a la disciplina y la praxis del Trabajo Social, concluyendo que existe una profunda conexión entre ambos. Este trabajo ha sido desarrollado en base a la revisión y análisis bibliográfico desde una perspectiva hermenéutica, relacionando texto con el contexto histórico y la práctica disciplinaria. En tal sentido, consideramos que volver la mirada al Pensamiento Crítico Latinoamericano, no sólo es una posibilidad de nutrir de nuevos marcos conceptuales referenciales, para la generación de conocimientos y para la acción transformadora, sino que una necesidad que se inscribe en las propias transformaciones de la sociedad actual.
\end{abstract}

PALABRAS CLAVE: Trabajo Social, Pensamiento Crítico Latinoamericano, conciencia crítica, educación popular.

\begin{abstract}
The central objective of this study was to analyze the contribution of Latinamerican critical thinking to the discipline and practice of social work, concluding that there is a deep connection between them. This study was developed through a revision of the state of the art and a biblographic analysis from a hermeneutic perspective. Examples are given of the contribution of Latin American critical thinking in a historic, disciplinary and practical context. It is proposed that looking to the Latin American way of critical thinking within social work is an opportunity to nurture new conceptual frameworks to generate knowledge


for transformative action in current society.

KEY WORDS: Social Work, Latin American Critical Thinking, critical conscience, popular education

\section{INTRODUCCIÓN}

Este ensayo tiene como finalidad, comprender críticamente los aportes del Pensamiento Latinoamericano a la disciplinaria y la praxis del Trabajo Social. En particular, lo anterior se plantea como una necesidad de revisar los aspectos epistemológicos y políticos, del Pensamiento Latinoamericano, y como ello se podría expresar, en un tipo de Trabajo Social, que disciplinariamente se distancie de la dominación intelectual eurocentrada y norteamericana. Y, en consecuencia, que su práctica, constituya una acción articulada con la reflexión teórica, orientada a la transformación de las diversas formas de dominación y exclusión.

Cabe recordar que, el Pensamiento Crítico y su filosofía de praxis liberadora, sufrió una especie de agotamiento e incluso hostigamiento académico y político, producto de las dictaduras militares, y del predominio de la ideología neoliberal, que permeabilizó los diferentes ámbitos de producción material y simbólica (Alemian, 2005; Borón, 2000, 2006). Durante gran parte de las últimas dos décadas del siglo pasado, se evidenciaba una suerte de relajamiento, si se comparaba con el fuerte impulso crítico de la década de los sesenta y setenta, caracterizado no solo por una prolífera producción intelectual, sino que además la propuesta emancipadora y proyectiva de una sociedad más justa e igualitaria, contenidas en el pensar de América latina.

Pero desde fines del siglo XX, el Pensamiento Latinoamericano, ha tenido un nuevo impulso, que vienen no sólo de los ámbitos académicos, sino que responde a una fuerte influencia de los movimientos sociales, que en sí mismo constituyen una nueva fuente de producción de conocimientos y de debate político (García, 2008; Quijano, 2005; Sader, 2009; Seaone \& Taddei, 2004; Seaone et al. 2006).

Las perspectivas orientadas a la des-colonización (Quijano, 2005), ha dado lugar a un rico debate, que ha reinstalado el Pensamiento Crítico, como un contra -discurso generado desde el margen, pero mirando al centro, como punto de referencia y de antagonismo (Dussel, 2011). Es decir, como práctica de resistencia y emancipación, de lo cual el Trabajo Social, debe hacerse parte, para reconfigurar su praxis transformadora, a la luz del nuevo escenario y del nuevo sujeto histórico.

El escenario de conflictividad presente en los distintos países de América Latina, ha permitido la visibilización de las profundas contradicciones generadas por el modo de producción colonial capitalista, en su fase neoliberal. Este campo de tensiones, ha reinstalado a los/as excluidos/as como el nuevo sujeto político y motor de la historia, resignificando la praxis sociopolítica. 
Los nuevos y diferentes actores de los sectores subalternos, permitiría a la disciplina reposicionarse, nutrirse desde una episteme latinoamericana, con nuevos marcos conceptuales, para desarrollar una praxis disciplinaria descolonizada. Esto requiere de un desplazamiento epistemológico y político, que parta por el reconocimiento de nuevos saberes, nuevas formas de saber, para abrirse a una nueva praxis disciplinaria, a la luz del nuevo escenario. Un punto de inflexión en la relación oprimido/opresor, instalada en la subjetividad y materialidad impuesta por los conquistadores que llegan a América, de la cual, como disciplina, nos empapamos en una doble dialéctica, expresada en el ser y el quehacer profesional.

En esta articulación entre el Pensamiento Latinoamericano y el Trabajo Social habría que tener presente tres elementos, que se irán desarrollando en este artículo: 1) El surgimiento del Pensamiento Latinoamericano, como un discurso ético-político contra-hegemónico; 2) El Trabajo Social, como una praxis socio-política, en donde el movimiento de reconceptualización, se inscribe como el punto de inflexión de la tecnocracia y conservadurismo disciplinario en términos teóricos y prácticos, y, 3) Contextualización histórica, en donde los nuevos movimientos sociales, se constituyen como el nuevo motor de la historia, aportando con nuevos conocimientos y práctica política, lo cual implica una importante fuente de saberes para los intelectuales críticos, y en consecuencia, generan las condiciones para una neoreconceptualización del trabajo social latinoamericano.

La relación del Trabajo Social con el Pensamiento Crítico Latinoamericano, representa una interpelación a la necesidad de ir nutriendo el contenido teórico con la praxis sociopolítica (Vivero, 2012a, 2012b) expresada en la acción profesional, con diferentes actorías en el actual momento histórico en América Latina. Cabe destacar que el Pensamiento Crítico Latinoamericano, no sólo pretende responde a la necesidad de una producción de conocimientos desde Latinoamérica y con ello dar cuenta de una particularidad epistémica, sino que este desafío intelectual y político, estimamos, se orienta fundamentalmente en dos ámbitos interrelacionados y que a nuestro juicio tiene una importante coincidencia y pertinencia al ethos del Trabajo Social: 1) instalar un debate crítico en torno a la ciencia del conocimiento que pude diferenciarse de las corrientes intelectuales occidentales y europeas que han sido hegemónicas y, 2) constituirse en un referente de conocimientos y prácticas que aporten a elevar los niveles de conciencia crítica para la liberación de las diferentes formas de dominación que viven los pueblos y sus gentes en Nuestra América Latina y Caribeña.

\section{LA RAZA COMO CONSTRUCCIÓN ONTOLÓGICA POLÍTICA DE LA COLONIALIDAD}

Con la llegada de los europeos, América se constituyó ontológica y políticamente como el campo geopolítico de dominación, de un nuevo patrón de poder construido, a partir de la negación y/o sometimiento de estos otros, de la raza no-blanca (Dussel, 2011, Quijano, 2005). Un espacio controlado por el centro a partir de la contradicción conquistador/conquistado, instalando en esta construcción ontológica-política la idea de raza, para diferenciar - a 
juicio de ellos - lo moderno de lo bárbaro. Para los conquistadores, esta nueva tierra, era el vasto imperio del diablo, de redención imposible o dudosa, por lo cual "la espada y la cruz marchaban juntas en la conquista y en el despojo colonial” (Galeano, 2005, p. 38)

Así entonces, la idea de reza, permitió "la codificación de las diferencias entre conquistadores y conquistados en la idea de raza, es decir, una supuesta diferente estructura biológica que ubicaba a los unos en situación natural de inferioridad respecto de los otros” (Quijano, 2005, p. 202). La concepción de raza, se posiciona como el argumento ideológico central de los europeos, para fundamentar, justificar y legitimar las relaciones de dominación que impusieron los conquistadores. De esta forma, se constituyen nuevas identidades históricas producidas sobre la base de la idea de raza, serán asociadas a la naturaleza de los roles y lugares en la nueva estructura global de control del trabajo (Dussel, 2011; Galeano, 2005; Quijano, 2005). De esta forma, se articulan y refuerzan mutuamente ambos elementos - raza y la división del trabajo para configurar una matriz ideológica, en la cual quedan estructuralmente asociados y permite justificar las prácticas de dominación y explotación, de los conquistadores primero, y más tarde de los países industriales del centro y las clases dominantes de los estados nacionales (Borón, 2000; Dussel, 2005, 2011; Galeano, 2005; Quijano, 2005).

Desde la llegada de los europeos a América, el Pensamiento Crítico Latinoamericano, representa en los ámbitos intelectuales y políticos, una importante expresión de lucha contra hegemónica. Un perspectiva crítica, que hace su incursión en la escena política e intelectual, con mayor fuerza en la década del sesenta y principios del setenta del siglo XX, donde destacamos el pensamiento y práctica pedagógica-política de Paulo Freire, Orlando Fals Borda (Devés, 2003), la Teología de la Liberación, con Gustavo Gutiérrez, Leonardo Boff, Carlos Libânio, la Filosofía de la Liberación, con Dussel, Hinkelammert, Leopoldo Zea, Augusto Salazar Bondy (Devés, 2003; Hinkelammert, 2001), por mencionar algunos.

El Pensamiento Latinoamericano, es una práctica filosofía crítica que surge desde el seno de América Latina. Entre sus hitos hay dos movimientos que dan cuenta de cómo se va articulando, en el mundo intelectual latinoamericano, una producción de conocimientos, que se sustenta en un profundo análisis de los conflictos y contradicciones históricas que viven los pueblos latinoamericanos. Este contra-discurso, que propone el Pensamiento Latinoamericano se fundamenta en una praxis emancipadora y descolonizadora (Dussel, 2005, 2011; Quijano, 2005; Sader, 2009). Una perspectiva y práctica político-intelectual que re-emerge a partir de la década del noventa del siglo $\mathrm{XX}$, que simbólicamente tiene mucho significado, porque coincide con los 500 años de la llegada de los españoles al "nuevo mundo". En este nuevo contexto, son los sectores oprimidos de América Latina, en particular las comunidades indígenas y campesinos, que comienzan a levantarse y a reconstruir el camino de la emancipación.

El levantamiento del Ejército Zapatista de Liberación Nacional (EZLN) el $1^{\circ}$ de enero de 1994, es un hito que marcará el inicio de una lucha por la liberación, que se verá replicada en otros pueblos indígenas y sectores urbanos populares, que levantarán ciclos con diferentes 
niveles de intensidad, como los Piqueteros en Argentina, los movimientos indígenas en Bolivia (conformación de la Coordinadora del Agua y la Vida, en lo que será la Guerra del Agua y más tarde la Guerra del Gas), el Movimiento de los Sin Tierra en Brasil (MST) y las históricas luchas del pueblo mapuche en el sur de Chile (García, 2008; Sader, 2009; Seaone \& Taddei, 2004, Seaone, Taddei, \& Algranati,2006).

El Pensamiento Crítico Latinoamericano, es un discurso y una práctica que se construye desde la periferia social, desde las clases oprimidas, desde los/as excluidos/as (Dussel, 2011). No es cualquier tipo de perspectiva intelectual y política, sino que es aquella que surge desde la exclusión y la subalteridad, provocada por el colonialismo europeo primero y luego por la consolidación de capitalismo industrial, hasta la hegemonía de la globalización capitalista neoliberal, genera ciertas condiciones materiales y subjetivas para repensar la formación y práctica disciplinaria.

\section{LA NEO-RECONCEPTUALIZACIÓN DEL TRABAJO SOCIAL Y PENSAMIENTO LATINOAMERICANO}

Entre las ideas propuestas en este trabajo, se plantea que existiría una complementariedad entre el Pensamiento Latinoamericano y el Trabajo Social, particularmente aquel que se sitúa desde una perspectiva crítica. Las tensiones y contradicciones generadas por el patrón de poder capitalista hegemónico, al interior de la disciplina se manifestaría en su nivel epistemológico (lo que se conoce y cómo se conoce) y en un nivel práctico (lo que se hace, por qué y cómo se hace). Esta tensión y conflictividad, fueron los puntos de discusión y propuesta transformadora, asumidas en el histórico movimiento de reconceptualización del Trabajo Social Latinoamericano, desde mediados de la década del sesenta hasta fines del setenta del siglo pasado.

Hoy si bien es cierto, estamos en un momento histórico distinto a aquel en que se desarrolla esta apuesta por la reconceptualización disciplinaria, estimamos que la crisis de hegemonía que experimenta el modo de producción capitalista neoliberal. Las consecuencias en el modo de vivir de la sociedad actual y en particular, las consecuencias perversas en las clases subalternas, con todas sus contradicciones materiales e intersubjetivas, hacen necesario que el Trabajo Social, se replantee ciertas cuestiones en el orden epistémico-político práctico (Vivero, 2017 a, 2017 b).

En la década del sesenta, en pleno proceso de reconceptualización, entre otros cuestionamientos, se ponía en discusión la naturaleza y esencia misma de la disciplina y el quehacer profesional. En tal sentido, se hacía un análisis crítico de ésta, concluyendo que su acción contribuye a la reproducción de la ideología y el conocimiento dominante (Iamamoto, 1992, Netto, 1992, 2012), y por tanto su práctica está limitada por el espacio que el aparato de dominación permite, en un determinado campo de acción. En tal escenario, el proceso de reconceptualización apostaba a que el proyecto histórico del Trabajo Social, estaba por la 
liberación de las masas oprimidas y el fin de las formas de dependencia y opresión (Alayón, 2005; Iamamoto, 1992, Netto, 1992, 2012)

Aquel escenario, a pesar de las distancias y diferencias históricas y políticas, lleva a preguntarnos respecto de los ethos que hoy mueven el ser y el quehacer del Trabajo Social, en tanto disciplina que tiene su génesis en la matriz capitalista y en la concepción de la racionalidad moderna (Aguayo, 2007, Netto, 1992, 2012). Las condiciones de desigualdad, las prácticas de exclusión y las diversas formas de opresión, si bien pueden presentar morfologías muy diferentes a aquellas planteadas en la perspectiva crítica de la reconceptualización, hoy sigue vigente el desafío ético y político del Trabajo Social: la liberación de las diversas formas de desigualdad y de exclusión, generadas por el modo de producción capitalista, hoy en su fase neoliberal globalizada.

En tal sentido, la perspectiva crítica del Pensamiento Latinoamericano, puede contribuir a nutrir la reflexión y la acción, orientada a la generación de un nivel de conciencia crítica al interior de la disciplina y en las contradicciones que se expresan en la relación pragmática con las estructuras de poder y con los sectores subalternos.

El Pensamiento Latinoamericano, es un soporte importante, coherente y pertinente para retomar la senda de la praxis consciente, concientizadora y liberadora como se planteó en los orígenes del proceso de reconceptualización. Creemos que esto, entre otras cosas, permitiría nutrirse y resignificar algunas categorías de análisis y formas de acción profesional, que conlleva, a un importante y urgente proceso de des-colonización del saber y del poder (Quijano, 2005). En consecuencia, esto apunta a develar las contradicciones propias del modelo hegemónico y de tal forma, comprender los procesos colectivos de los diversos ámbitos (Borón, 2000, 2003, 2006; Quijano, 2005), que nos permita una mayor conexión con ellos y desarrollar una acción profesional con pertinencia intercultural, orientada a la transformación social.

Volver la mirada al Pensamiento Crítico Latinoamericano, no sólo es una posibilidad de nutrir de nuevos marcos conceptuales referenciales, para la generación de conocimientos y para la acción transformadora, sino que una necesidad que se inscribe en las propias transformaciones de la sociedad actual, y la emergencia de una serie de complejas problemáticas, productos de un modelo de sociedad, en que las expectativas de vida, especialmente las de orden material, se multiplican, al mismo tiempo que se reducen las posibilidades de que estas sean alcanzadas.

El arsenal conceptual que se desprende desde el Pensamiento Latinoamericano es extenso, por lo cual tomaremos algunos elementos, pertinentes y necesarios para poner en discusión la necesidad de una articulación entre el Trabajo Social Crítico y esta corriente intelectual. Esta articulación, estimamos, generaría las condiciones para lo que hemos denominado una neo-reconceptualización disciplinaria.

En tal sentido, la conciencia crítica, la concientización, la necesidad de auto-conocer las peculiaridades del continente y la búsqueda de la emancipación y las luchas anticoloniales 
(Devés, 2003; Quijano, 2005), lo entendemos como contenidos fundamentales en la producción intelectual y política latinoamericana. Esto sigue estando presente en Pensamiento Crítico Latinoamericano, y para el Trabajo Social constituye un recurso epistémico para el análisis, la reflexión teórica y de sustento en las metodologías de la acción profesional. Esto sin desconocer que, pueden emerger otras categorías de análisis para la reflexión y práctica disciplinaria.

Coincidiendo con algunos autores (Borón, 2000, 2003, 2006; Dussel, 2005; Seaone \& Taddei, 2004, Seaone, Taddei, \& Algranati, 2006), se considera que el escenario actual, presenta una notoria agudización de las desigualdades, como consecuencia del modelo de acumulación capitalista globalizado. Pero a la vez, esto mismo ha permitido una revitalización, un nuevo impulso del Pensamiento Latinoamericano, lo cual tiene la particularidad de estar impregnado de una fuerte influencia de los movimientos sociales, que en sí mismo constituyen una nueva fuente de producción de conocimientos y de debate político. Los movimientos sociales, han nutrido de contenido discursivo y políticos a la intelectualidad latinoamericana (Borón, 2000, 2003, 2006; Dussel, 2005; Seaone \& Taddei, 2004, Seaone, Taddei, \& Algranati, 2006).

Para el Trabajo Social Crítico, resulta necesario retomar la senda trazada por la tradición del pensamiento latinoamericano, como la praxis consciente, concientizadora y liberadora. Fundamentos que tienen plena sintonía con los sustentos que se planteó el proceso de reconceptualización (Vivero, 2016, 2017a, 2017b). Como señalábamos más arriba, retomar esta perspectiva, entre otras cosas, permitiría nutrirse y resignificar algunas categorías de análisis y formas de acción profesional, que conlleva, a un importante y urgente proceso de des-colonización del saber y del poder (Quijano, 2005). Esto contribuye al develamiento de las contradicciones propias del modelo hegemónico y cómo esto, se expresa material y simbólicamente en las personas, grupos y comunidades con las que actuamos en la cotidianeidad.

Se puede entender, por tanto, que, en el ethos de los intelectuales críticos latinoamericanos, está presente una postura de carácter ético político, que busca abrirse a la reflexión sobre las históricas condiciones de dominación sufridas por el continente. Ethos que por lo mismo, tiene una profunda conexión con lo que desde la perspectiva crítica del Trabajo Social se postula, por lo cual la articulación disciplinaria y práctica con esta corriente de pensamiento, no hace sino que reforzar y nutrir de mayor sentido ético y político la praxis profesional (Vivero, 2012a, 2012b, 2016, 2017a, 2017b)

La conciencia crítica y concientización, es tal vez una de las tantas categorías características de lo que fue y sigue siendo el Pensamiento Crítico Latinoamericano. La concientización, se da tras los avances del hombre en proceso evolutivo, el espíritu humano surge como el ser que tiene la capacidad de autoposeerse a sí mismo, es decir tener conciencia de sí, a la vez de él en el mundo y en la historia.

En la misma línea anterior, la educación liberadora, desarrollada por Paulo Freire, pasa desde una posición inicial de "intransitividad de conciencia" a una "conciencia crítica", que en 
definitiva es lo que permite la liberación tanto del oprimido como del opresor (Freire, 2004, p. 55). Por lo tanto, "la conciencia del mundo y la consciencia de mí no me hacen un ser en el mundo, sino con el mundo y con los otros; un ser capaz de intervenir en el mundo y no solo de adaptarse a él” (Freire, 2001, p. 50). Entonces, es el diálogo consciente, en que el hombre y la mujer aprehenden el mundo y son con el mundo mismo, reconociendo los desafíos y problemas que enfrentan. La educación liberadora, por lo tanto, es histórica y crítica en el cual "los oprimidos van descubriendo el mundo de la opresión y se van comprometiendo en la praxis, con su transformación (...)” (Freire, 2002, p. 55).

Es importante también señalar que la reflexión al interior de la corriente de Pensamiento Crítico no sólo se centra en un cuestionamiento a las formas de dominación occidental, sino que, al interior mismo de este, lo cual tiene mucho sentido con lo que fue el proceso de reconceptualización en trabajo social, y por lo mismo en la actual necesidad de una mirada crítica de la disciplina y la acción profesional en el actual escenario sociopolítico (Vivero, 2012 a, 2012 b, 2016, 2017 a, 2017b).

Hoy más que nunca, este pensar y actuar se inscribe “desde la periferia política, porque dominados o coloniales, desde la periferia económica, porque colonos, desde la periferia geopolítica, porque excluidos, (...)” (Dussel, 2011, p. 20). Ergo, nos preguntamos si el Trabajo Social, está dispuesto a levantar una lectura crítica a nivel disciplinario y práctico, tomando como referencia histórica y política, las luchas y transformaciones que están llevando a delante los sectores excluidos a los cuales declaramos apoyar en sus demandas, sus problemáticas y sus necesidades.

\section{REFLEXIONES FINALES}

Los movimientos sociales constituyen un motor relevante en todo proceso de cambio, generado desde las clases subalternas, cuestión que en el actual momento histórico, se manifiesta como una realidad material e intersubjetiva, que el Trabajo Social debe tener en consideración, para resignificar sus marcos conceptuales operativos, y sus prácticas a nivel socio-familiar, grupal y/o colectivo, sobre todo, si se quiere ser parte o contribuir a las transformaciones que reclaman los sectores excluidos.

En el actual escenario en que se visualiza una dicotomía en torno a la hegemonía neoliberal, en donde aparecen por un lado procesos que ponen en cuestionamiento y disputa dicho control y, por otro lado, contextos en que este dominio pareciera mantenerse y consolidarse. Sin embargo, lo que no se puede dejar de considerar, es que este nuevo ciclo de conflictividad social está protagonizado por nuevos sujetos colectivos ${ }^{1}$, en que su acción ha contribuido a abrir una crisis de legitimidad y de hegemonía del modelo neoliberal en toda

\footnotetext{
Aquí el apelativo de "nuevo" lo hacemos para marcar la distinción con el sujeto colectivo definido por el marxismo clásico, de los procesos que marcaron gran parte del siglo XX, representado de acuerdo a esta tradición ideológica, en la clase obrera como el motor de la historia. A esto cabe agregar que el movimiento indígena se ha constituido como uno de los más relevantes del ciclo de protestas inaugurado a fines del siglo y que continúa con distintos matices en los años vividos del presente siglo.
} 
Latinoamérica. A ello habría que agregar que ésta conflictividad se constituye en el centro mismo de esta nueva etapa del movimiento mundial de la sociedad contra el capitalismo colonial/moderno.

Este nuevo escenario debe constituirse para el Trabajo Social, como el campo que permita retomar no sólo la línea de producción teórica-práctica, sino que por, sobre todo, su compromiso político con los sectores subalternos, visibilizando aquellos actores que las elites políticas e intelectuales tratan de mantener en la oscuridad.

Hay que reconocer, además, que son los movimientos sociales los que han nutrido de nuevos sentidos y significados la producción intelectual latinoamericana, siendo por tanto ellos, los protagonistas principales no sólo de los procesos sociopolíticos, sino que del nuevo contenido político y simbólico del discurso de los intelectuales críticos. Esto, por lo tanto, representa también una revolución epistemológica, que implica un quiebre de la hegemonía de los intelectuales, una apertura a la construcción, reconocimiento de saberes diversos y a una democratización de conocimientos.

El significado axiológico y político del Pensamiento Crítico y del Trabajo Social Crítico, sin duda nos deja planteado el gran desafío de profundizar la discusión sobre ello. Ahora, a la luz de las transformaciones sociopolíticas en el último cuarto de siglo en nuestra América Latina y caribeña, continuamos preguntándonos qué significa hoy, un Pensamiento Crítico propiamente latinoamericano y una práctica social crítica. Pregunta que cierto no es nada de novedosa, pero que consideramos como necesaria dejar instalada en esta reflexión.

Habría que repensar el Trabajo Social y fundamentalmente su dimensión política, que reproduce en sus prácticas consientes o inconscientes, la matriz propia de la ideología neoliberal, partiendo por la separación entre lo social y lo político. De manera insoslayable, dicha separación, no sólo contribuye al fortalecimiento del Estado neoliberal, sino que perpetúa las formas de dominación y exclusión. Lejos de contribuir a la construcción de una sociedad más justa, acrecienta las injusticias sociales, que es la antítesis a las declaraciones axiológicas de Trabajo Social y del Pensamiento Crítico Latinoamericano.

La ruptura epistémica-política con la matriz conservadora del Trabajo Social, hoy tributaria de la ideología neoliberal, debe representar la consecuencia y coherencia con los discursos críticos, si quiere ser parte contribuyente de las transformaciones que se están fraguando. De lo contrario, la disciplina seguirá relegada a un nivel eminentemente tecno - asistencial- burocrático, como instrumento de control y dominación de las clases dominantes, y etiquetadores de la desigualdad por medio de la operacionalización de las distintas estrategias de contrainsurgencia social, expresadas en las políticas públicas y sociales. No se trata de que todo el ámbito disciplinario deba instalarse en el campo de lo crítico, pero tampoco puede seguir esta hegemonía de las corrientes conservadoras y neoconservadoras. En definitiva, si no se da un paso rupturista con las lógicas conservadoras acríticas, despolitizadas y deshistorizadas, el Trabajo Social no será más que parte de los cuadros intelectuales orgánicos y operativos de las clases dominantes. 


\section{REFERENCIAS}

Aguayo, C. (2007). Las profesiones modernas: dilemas del conocimiento y del poder, Argentina: Espacio.

Alayón, N. (Ed.). (2005). Trabajo Social Latinoamericano. A 40 años de la Reconceptualización. Buenos Aires: Espacio.

Alemian, C. (2005). Praxis. En R. Salas (Ed.), Pensamiento crítico latinoamericano Vol. III (pp. 833-850). Santiago de Chile: Universidad Católica Silva Henríquez.

Boron, A. (2000). Tras el Búho de Minerva. Mercado contra democracia en el capitalismo de fin de siglo. Argentina: Fondo de Cultura Económica.

Borón, A. (2003). Estado, capitalismo y democracia, Buenos Aires: CLACSO.

Borón, A. (2006). "Las ciencias sociales en la era neoliberal: entre la academia y el pensamiento crítico", en Tareas No 122. CELA, Centro de Estudios Latinoamericanos "Justo Arosemena." Artículo recuperado de http://bibliotecavirtual.clacso.org.ar/panama/cela/tareas/ tar122/03boron.pdf, fecha de consulta 26 enero 2014.

Devés, E. (2003). El pensamiento latinoamericano en el siglo XX. Tomo II: Desde la CEPAL al neoliberalismo (1950-1990), Argentina: Editorial Biblos.

Dussel, E. (2005). Europa, modernidad y eurocentrismo. En E. Lander (Coord.), La colonialidad del saber: eurocentrismo y ciencias sociales. Perspectivas latinoamericanas (pp. 41-54). Buenos Aires: CLACSO.

Dussel, E. (2011). Filosofía de la liberación, México, D.F: Fondo De Cultura Económica.

Freire, P. (2001). Pedagogía de la indignación, Madrid: Ediciones Morata.

Freire, P. (2002). Pedagogía de la esperanza. Un reencuentro con la Pedagogía del Oprimido, Buenos Aires: Siglo XXI.

Freire, P. (2004). La educación como práctica de la libertad, Argentina: Siglo XXI.

Galeano, E. (2005). Las venas abiertas de América Latina, Santiago: Pehuén.

García, Á. (2008). La potencia plebeya. Acción colectiva e identidades indígenas, obreras y populares en Bolivia, Buenos Aires: Prometeo Libros.

Hinkelammert, F. (2001). El nihilismo al desnudo. Los tiempos de la globalización, Chile: LOM. Iamamoto, M. (1992). Servicio Social y División del Trabajo. Un análisis crítico de sus fundamentos. São Paulo: Cortez.

Netto, J. P. (1992). Capitalismo Monopolista y Servicio Social. São Paulo: Cortez.

Netto, J. P. (2012). Trabajo Social: Crítica de la vida cotidiana y método en Marx. La Plata Argentina: Productora del Boulevard.

Quijano, A. (2005). Colonialidad del poder, eurocentrismo y América latina. En Edgardo Lander (coord.): La colonialidad del saber: eurocentrismo y ciencias sociales. Perspectivas latinoamericanas, Buenos Aires, CLACSO. pp. 201-246.

Sader, E. (2009). El nuevo topo. Los caminos de la izquierda Latinoamericana, Buenos Aires: Siglo XXI. 
Seaone, J., \& Taddei, E. (2004). Movimientos sociales, democracia y gobernabilidad neoliberal en América latina, Buenos Aires, CLACSO. Artículo recuperado de http://biblioteca. clacso.edu.ar/gsdl/collect/clacso/index/assoc/D3727.dir/10intro15.pdf, fecha consulta 18 noviembre 2013

Seaone, J., Taddei, E., \& Algranati, C. (2006). Las nuevas configuraciones de los movimientos populares en América Latina. En Atilio Boron; Lechini Gladys Publicación: Política y movimientos sociales en un mundo hegemónico. Lecciones desde África, Asia y América Latina, Buenos Aires: CLACSO. Artículo recuperado de http://biblioteca.clacso.edu.ar/ ar/libros/sursur/politica/PIIICuno.pdf fecha consulta 23 julio 2012

Vivero, L. (2012a). Aprendizajes y desafíos para el trabajo social a la luz del movimiento estudiantil en Chile. Revista Margen, 65.

Vivero, L. (2012b). Cambios sociopolíticos en América Latina: Desafíos para un trabajo social crítico latinoamericano. Revista Eleuthera, 6, 15-25

Vivero, L. (2016). El Trabajo Social en la era neoliberal: Desafíos para una neoreconceptualización. En P. Vidal (Coord.), Trabajo Social en Chile: Un siglo de Trayectoria (pp. 175-195). Chile: Editorial Ril.

Vivero L. (2017a). Influencia del neoliberalismo en el Trabajo Social chileno: Discursos de profesionales y usuarios. Revista Colombiana de Ciencias Sociales, 8(1), pp. 125-148.

Vivero, L. (2017b). Trabajo Social entre el sentido común, hegemonía y praxis: Un análisis desde Gramsci. Revista Latinoamericana de Ciencias Sociales, Niñez y Juventud,15(1), 547-563. 